\title{
RESEARCH
}

Open Access

\section{Genome-wide identification of long noncoding RNAs and their competing endogenous RNA networks involved in the odontogenic differentiation of human dental pulp stem cells}

Zhao Chen ${ }^{1}$, Kaiying Zhang ${ }^{1}$, Wei Qiu', Yifei Luo ${ }^{1}$, Yuhua Pan ${ }^{1}$, Jianjia Li ${ }^{1}$, Yeqing Yang ${ }^{1}$, Buling $\mathrm{Wu}^{1,2^{*}}$ and Fuchun Fang ${ }^{1,2^{*}}$

\begin{abstract}
Background: Long noncoding RNAs (IncRNAs) play an important role in the multiple differentiations of mesenchymal stem cells (MSCs). However, few studies have focused on the regulatory mechanism of IncRNAs in the odontogenic differentiation of human dental pulp stem cells (hDPSCs).

Methods: hDPSCs were induced to differentiate into odontoblasts in vitro, and the expression profiles of IncRNAs, microRNAs (miRNAs), and messenger RNAs (mRNAs) in differentiated and undifferentiated cells were obtained by microarray. Bioinformatics analyses including Gene Ontology $(\mathrm{GO})$ analysis, pathway analysis, and binding site prediction were performed for functional annotation of IncRNA. miRNA/odontogenesis-related gene networks and IncRNA-associated ceRNA networks were constructed. Quantitative reverse-transcription polymerase chain reaction (qRT-PCR) was used to verify the expression of selected genes. RNA fluorescence in situ hybridization (FISH), qRTPCR, and western blot analysis were used to explore the location and function of IncRNA-G043225. Dual-luciferase reporter assay was performed to confirm the binding sites of miR-588 with G043225 and Fibrillin 1 (FBN1).

Results: We identified 132 IncRNAs, 114 miRNAs, and 172 mRNAs were differentially expressed. GO analysis demonstrated that regulation of the neurogenic locus notch homolog (Notch), Wnt, and epidermal growth factor receptor (ERBB) signaling pathways and activation of mitogen-activated protein kinase (MAPK) activity were related to odontogenic differentiation. Pathway analysis indicated that the most significant pathway was the forkhead box $\mathrm{O}$ (FoxO) signaling pathway, which is related to odontogenic differentiation. Two odontogenesis-related genecentered IncRNA-associated ceRNA networks were successfully constructed. The qRT-PCR validation results were consistent with the microarray analysis. G043225 mainly locating in cytoplasm was proved to promote the odontogenic differentiation of hDPSCs via miR-588 and FBN1.

(Continued on next page)
\end{abstract}

\footnotetext{
* Correspondence: bulingwu@smu.edu.cn; fangfuchun520@163.com

'Department of Stomatology, Nanfang Hospital, Southern Medical University,

Guangzhou 510515, Guangdong, People's Republic of China

${ }^{2}$ College of Stomatology, Southern Medical University, Guangzhou 510515,

Guangdong, People's Republic of China
}

C C The Author(s). 2020 Open Access This article is licensed under a Creative Commons Attribution 4.0 International License, which permits use, sharing, adaptation, distribution and reproduction in any medium or format, as long as you give appropriate credit to the original author(s) and the source, provide a link to the Creative Commons licence, and indicate if changes were made. The images or other third party material in this article are included in the article's Creative Commons licence, unless indicated otherwise in a credit line to the material. If material is not included in the article's Creative Commons licence and your intended use is not permitted by statutory regulation or exceeds the permitted use, you will need to obtain permission directly from the copyright holder. To view a copy of this licence, visit http://creativecommons.org/licenses/by/4.0/ The Creative Commons Public Domain Dedication waiver (http://creativecommons.org/publicdomain/zero/1.0/) applies to the data made available in this article, unless otherwise stated in a credit line to the data. 
(Continued from previous page)

Conclusion: This is the first study revealing IncRNA-associated ceRNA network during odontogenic differentiation of hDPSCs using microarray, and it could provide clues to explore the mechanism of action at the RNA-RNA level as well as novel treatments for dentin regeneration based on stem cells.

Keywords: Competing endogenous RNA, Human dental pulp stem cells, Long noncoding RNA, MicroRNA, Odontogenic differentiation,

\section{Introduction}

Human dental pulp stem cells (hDPSCs) are derived from the ectoderm and originate from neural crest cells, and have the ability to self-renew and undergo multipotential differentiation [1-3]. hDPSCs can differentiate into osteoblasts, chondrocytes, adipocytes, neurons, and odontoblasts [4-8]. Due to their capability to differentiate into odontoblasts, hDPSCs play an important role in dentin repair and regeneration, which provides a new approach for regeneration treatment of dental tissue in clinical applications $[9,10]$. However, the specific molecules and mechanisms involved in the odontogenic differentiation process of hDPSCs are still unclear and require further research.

Long noncoding RNA (lncRNA) is defined as a noncoding ribonucleic acid with a length of more than 200 nucleotides and that lacks protein-encoding capacity [11]. Increasing evidence has confirmed that lncRNAs are widely involved in the biological processes including but not limited to DNA methylation, histone modification, and chromatin remodeling and can interact with DNA, RNA, and protein molecules to regulate the expression of target genes via cis or trans mode [12-14]. Although two lncRNAs have been shown to regulate odontogenesis $[15,16]$, the roles of most lncRNAs in this process are unknown.

Many studies have shown that the expression of a number of lncRNAs may be related to cell proliferation, apoptosis, migration, and differentiation [17-19]. IncRNAs can regulate gene expression through a variety of mechanisms. For example, lncRNA can directly bind to homologous genomic DNA and RNA, or they can interact with many proteins by forming complex secondary structures and regulate gene expression at the transcriptional, posttranscriptional, and epigenetic levels $[20,21]$. In these various mechanisms, lncRNA can act as a sponge to competitively bind to microRNA (miRNA), resulting in changes in the protein level of coding genes at posttranscriptional level [22]. The current study explored the IncRNA, miRNA, and messenger RNA (mRNA) profiles during odontogenic differentiation of hDPSCs using microarray. Gene Ontology (GO) and pathway analysis were carried out to explore the specific functions of lncRNAs. miRNA/target network and lncRNA-associated competing endogenous RNA (ceRNA) network centered on odontogenesis-related genes were constructed using bioinformatics analyses. The quantitative reverse-transcription polymerase chain reaction (qRT-PCR) method was used to validate the microarray results. LncRNA-G043225 was selected for further research according to the IncRNA-associated ceRNA network, and it might be involved in the process of odontogenic differentiation of hDPSCs through its sponge effect. Our research expands the potential lncRNA-associated ceRNA functions during odontogenic differentiation of hDPSCs and enhances the understanding of noncoding RNA (ncRNA) regulatory networks.

\section{Materials and methods \\ hDPSC isolation, culture, and identification}

Healthy premolars were extracted from 19 healthy adults ( 8 males and 11 females, aged from 15 to 25 years old, mean age 19.7) who were undergoing orthodontic treatment at the Department of Stomatology, Nanfang Hospital, Southern Medical University. This study was approved by the Ethics Committee of Nanfang Hospital, Southern Medical University. Written informed consent was obtained from all adult patients. For minor population, statement on informed consent was obtained from their parents. hDPSCs were cultured as previously described [23]. Isolated hDPSCs were cultured in Dulbecco's modified Eagle's medium (DMEM) (Gibco, Grand Island, NY, USA) supplemented with $10 \%$ fetal bovine serum (FBS) (Gibco, Grand Island, NY, USA) and $100 \mathrm{U} / \mathrm{mL}$ penicillin/streptomycin (HyClone, NY, USA), and maintained at $37^{\circ} \mathrm{C}$ in a humidified atmosphere with $95 \%$ air and $5 \% \mathrm{CO}_{2}$. A single-cell suspension was obtained by filtering cells through a $70-\mu \mathrm{m}$ filter (BD Falcon, Franklin Lakes, NJ). Singlecell suspensions were inoculated into six-well plates at a density of $1 \times 10^{4}$ cells/well. Limited dilution techniques were used to obtain colonies of single-cell origin [24].

Cells were characterized by using stem cell surface markers through flow cytometry (Becton Dickinson, Tokyo, Japan). hDPSCs were suspended in phosphate-buffered saline (PBS) containing 2\% FBS and incubated with antibodies on ice for $30 \mathrm{~min}$. The following antibodies were used: anti-phycoerythrin (PE), anti-fluorescein iso thiocyanate (FITC), (BD Pharmingen, Franklin Lakes, NJ). Isotypeidentical antibodies were used as controls. All procedures 
were carried out in darkness at $4{ }^{\circ} \mathrm{C}$. The expression profiles were determined by flow cytometer.

\section{Odontogenic induction}

hDPSCs in the differentiated group were cultured with an odontogenic differentiation medium containing $50 \mathrm{mg} / \mathrm{mL}$ ascorbic acid, $100 \mathrm{nmol} / \mathrm{L}$ dexamethasone, and $10 \mathrm{mmol} / \mathrm{L} \beta$-glycerophosphate (Sigma, St Louis, MO, USA) for 14 days in 6-well plates. hDPSCs in the undifferentiated group were cultured in $10 \%$ FBS in DMEM with no supplements. Then, the cells were rinsed 3 times with PBS, fixed in $4 \%$ formaldehyde for $30 \mathrm{~min}$, and stained with $2 \%$ Alizarin Red (Alizarin Red S A5533, Sigma-Aldrich) at room temperature for $10 \mathrm{~min}$. After washing several times with deionized water, calcium nodules were observed with a microscope (Crystal violet, Amresco, Solon, OH). For ALP staining, cells were cultured in odontogenic differentiation medium for 7 days and then stained. ALP staining was performed using the NBT/BCIP Staining Kit (Beyotime Biotech, Shanghai, China) following the protocol.

\section{Preparation of RNA samples}

According to the manufacturer's protocol, total RNA was isolated from cultured cells by TRIzol reagent (Thermo Fisher Scientific, Waltham, MA). The quantity and quality of RNA were determined by using ND-1000 spectrophotometer (NanoDrop Technology Company, Wilmington, DE) and Agilent 2100 Biological Analyzer (Agilent Technologies, Santa Clara, CA).

\section{IncRNA/mRNA and miRNA microarray}

Arraystar Human LncRNA Expression Array V4.0 (KangChen Bio-tech, Shanghai, China) detected 40, 173 lncRNAs and 20,730 protein encoded transcripts. Among them, IncRNAs were carefully selected from authoritative public transcriptome databases (RefSeq, UCSC Known Genes, Gencode, etc.) and high impact factor papers. Detailed microarray data about lncRNA and mRNA has been deposited at Gene Expression Omnibus (http://www.ncbi.nlm.nih.gov/geo; GSE138179).

The Whole Human microRNA (miRNA) microarray (KangChen Bio-tech, Shanghai, China) was used to perform expression profiling of all known miRNAs in the human transcriptome. The sequence was compiled from an extensive literature and database survey and then verified and optimized by comparison with the assembled human transcriptome. Detailed microarray data about miRNA has been deposited at Gene Expression Omnibus (http://www.ncbi.nlm.nih.gov/geo; GSE138180).

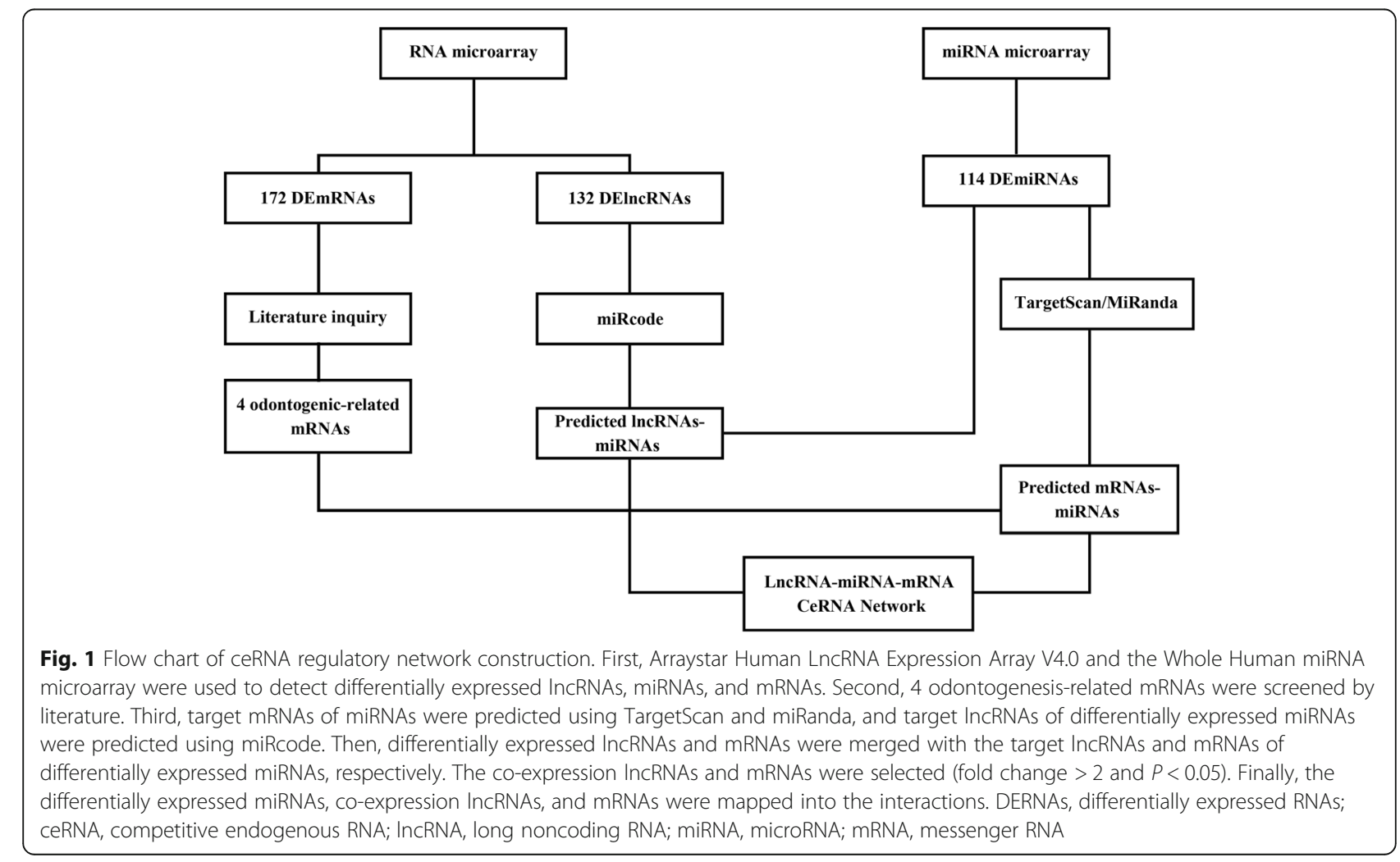


Table 1 Primer sequences for quantitative reverse-transcription polymerase chain reaction

\begin{tabular}{|c|c|}
\hline Gene & Sequence $5^{\prime} \rightarrow 3^{\prime}$ \\
\hline \multirow[t]{2}{*}{$\mathrm{RHO}$} & Forward: TCCAGTTTCCCTTGCCAGAC \\
\hline & Reverse: TGGAGAAGGGGGAGCAGTTA \\
\hline \multirow[t]{2}{*}{ FBN1 } & Forward: GCGGAAATCAGTGTATTGTCCC \\
\hline & Reverse: CAGTGTTGTATGGATCTGGAGC \\
\hline \multirow[t]{2}{*}{ NKD2 } & Forward: AGCGCAGATGACGGAGAGA \\
\hline & Reverse: CGAGACATCGCACTGGAGT \\
\hline \multirow[t]{2}{*}{ DDIT3 } & Forward: GGAAACAGAGTGGTCATTCCC \\
\hline & Reverse: CTGCTTGAGCCGTTCATTCTC \\
\hline \multirow[t]{2}{*}{ RP11-475|24.3 } & Forward: AGTGGACGTAGTTATTAAATGCTG \\
\hline & Reverse: CTGTGAGGACATAGGTGGTGGAG \\
\hline \multirow[t]{2}{*}{ RP11-17A4.1 } & Forward: ACGTACACGTTATGCCACCACTG \\
\hline & Reverse: CACGGAATCCATGCCTGAATCTA \\
\hline \multirow[t]{2}{*}{ G043225 } & Forward: GAGCCCGAATGTGACTAAA \\
\hline & Reverse: GTGGTGGTTGCAGAAGGT \\
\hline \multirow[t]{2}{*}{ G055009 } & Forward: TCCTGATGGAGGTGAGCG \\
\hline & Reverse: GCCTGGGTCCTGGAGAAA \\
\hline \multirow[t]{2}{*}{ G045900 } & Forward: GGAGTGGTCTGCTGGAGTTTGC \\
\hline & Reverse: GGTCCCTGGCCCTCATGTATCC \\
\hline \multirow[t]{2}{*}{ G019359 } & Forward: AGGGCACCCAGGACTTCAGATG \\
\hline & Reverse: TGTGTGGTGGGGTGGTTACTGG \\
\hline \multirow[t]{2}{*}{ G018548 } & Forward: TCCGCCTCCTGGGTTCAAGTG \\
\hline & Reverse: TGGCTGGGTGTGGTGGCTTAC \\
\hline \multirow[t]{2}{*}{ G012997 } & Forward: GGGAGGGTCTGGGACTCAAGTG \\
\hline & Reverse: CCCGCACTGGCACTCACATAC \\
\hline \multirow[t]{2}{*}{ G003293 } & Forward: CTCCAGCTCACGTTCCCTA \\
\hline & Reverse: TCGATGTCGGCTCTTCCT \\
\hline \multirow[t]{2}{*}{ G000862 } & Forward: GCTGTGCTCCGCTGAAGACTC \\
\hline & Reverse: TTGCCTGCTGCCGTGTAAGATG \\
\hline $\operatorname{miR}-32-5 p$ & Forward: CCTTGGCCACAATGGGTTAGAAC \\
\hline miR-588 & Forward: CCGCTATTGCACATTACTAAGTTGCA \\
\hline miR-4717-3p & Forward: TATATAACACATGGGTGGCTGTGGCCT \\
\hline \multirow[t]{2}{*}{ GAPDH } & Forward: CTGGGCTACACTGAGCACC \\
\hline & Reverse: AAGTGGTCGTTGAGGGCAATG \\
\hline \multirow[t]{2}{*}{ U6 } & Forward: CTCGCTTCGGCAGCACA \\
\hline & Reverse: AACGCTTCACGAATTTGCGT \\
\hline
\end{tabular}

RHO rhodopsin, FBN1 Fibrillin 1, NKD2 NKD inhibitor of WNT signaling pathway 2, DDIT3 DNA damage inducible transcript 3, GAPDH glyceraldehyde-3-phosphate dehydrogenase

\section{Construction of miRNA/targets and ceRNA networks and prediction of binding sites}

A regulatory network of differentially expressed miRNAs and odontogenesis-related targets was constructed using the TargetScan and miRanda databases.
In the ceRNA mechanism, noncoding RNA transcripts can interfere with each other by competing for binding with mRNAs, and RNA reaction elements are the basis of this interaction [25]. These RNA transcripts are called ceRNAs [26]. To find potential targets of miRNAs, target prediction based on TargetScan and miRanda was carried out [27-30]. By merging common target miRNAs, we built ceRNA networks (Fig. 1). The prediction of binding sites between mRNAs and miRNAs, and miRNAs with lncRNAs was carried out by retrieving the TargetScan and miRanda data and was performed by using a homemade software (KangChen Bio-tech, Shanghai, China).

\section{Functional enrichment analysis}

The GO database provides a controlled vocabulary to describe genes and gene product attributes in organisms (http://www.geneontology.org). Ontology covers three fields: biological processes (BP), cellular components $(C C)$, and molecular functions (MF). ( $P$ value $<0.05$ was used). The pathway analysis was based on the Kyoto Encyclopedia of Genes and Genomes (KEGG) pathway database. The $P$ value indicates the importance of the path related to the condition (the recommended critical $P$ value was 0.05$)$.

\section{Lentivirus construction and infection}

The G043225-specific oligoribonucleotide shRNA-G043225 and control oligoribonucleotide shRNA-ctrl were designed and synthesized by GeneChem Technology (Shanghai, China). The hDPSCs were seeded in 12-well plates at a density of $3 \times 10^{4}$ cells/well and cultured for $24 \mathrm{~h}$. They reached approximately $50 \%$ confluence at the time of infection. The cells were infected at a multiplicity of infection (MOI) of 50 in the presence of $5 \mathrm{mg} / \mathrm{mL}$ polybrene for $10 \mathrm{~h}$ at $37{ }^{\circ} \mathrm{C}$ and $5 \% \mathrm{CO}_{2}$. The knockdown efficiency was evaluated using fluorescence microscopy (Olympus, Tokyo, Japan) and qRT-PCR after infection for 3 days.

\section{RNA fluorescence in situ hybridization}

The RNA fluorescence in situ hybridization (FISH) procedure was performed using the RNA FISH Kit (GenePharma, Shanghai, China) following the manufacturer's protocol. Briefly, hDPSCs were seeded in 48-well plate and rinsed in PBS, then fixed in $4 \%$ paraformaldehyde solution for $15 \mathrm{~min}$ at room temperature. Next, cells were incubated with $0.1 \%$ Triton X-100 for $15 \mathrm{~min}$. Fluorescence-conjugated G043225 probes were used to perform hybridization in the dark overnight, washed with $0.1 \%$ Tween 20 for $5 \mathrm{~min}$ and formamide: $2 \times$ saline sodium citrate (SSC; $50: 50$ ) for $5 \mathrm{~min}$ at $42^{\circ} \mathrm{C}$. Cell nuclei were stained with $4^{\prime}, 6$-diamidino-2-phenylindole (DAPI) solution. Fluorescence images were obtained by fluorescence microscopy (Olympus, Tokyo, Japan), and representative pictures were shown. 

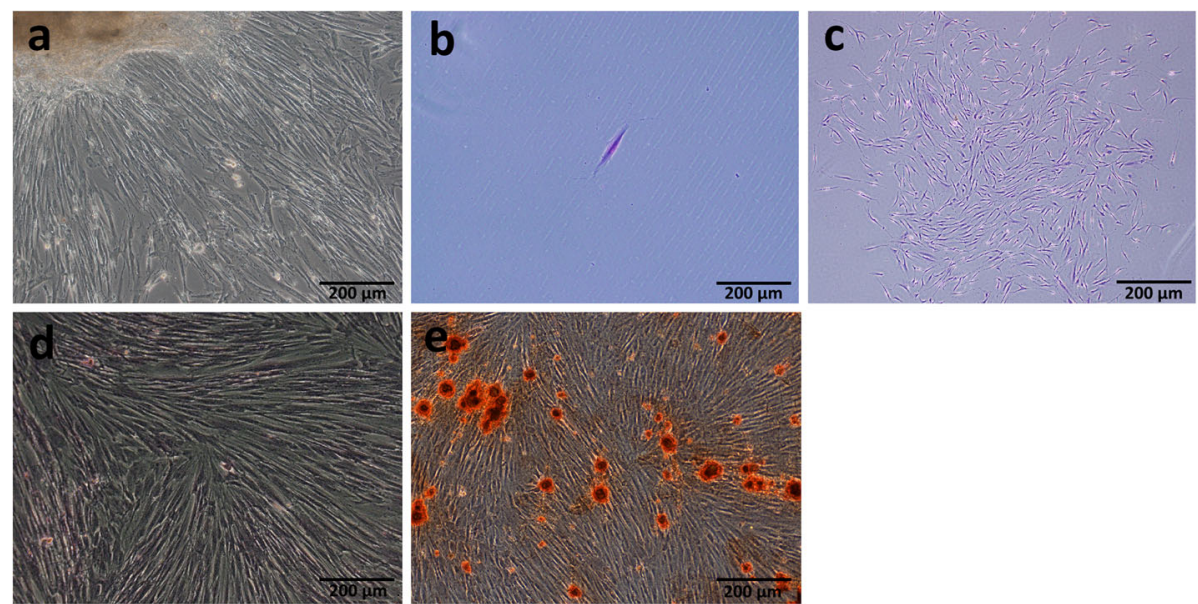

f
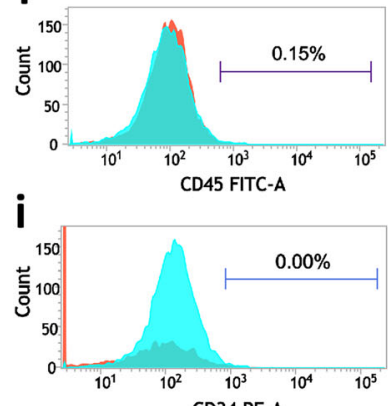

g
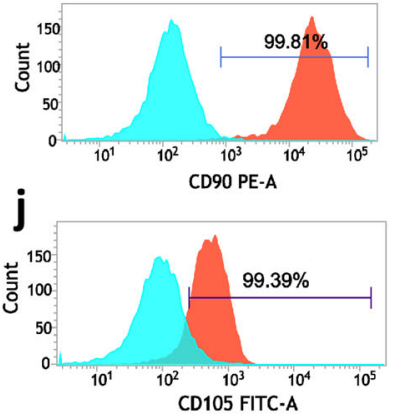

h

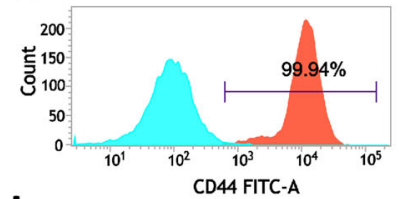

k

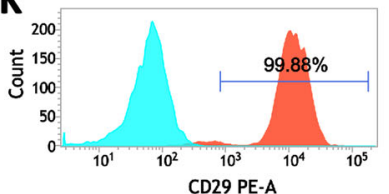

Fig. 2 Culture and identification of hDPSCs. a Primary cultured hDPSCs ( $\times 100)$. b A single cell was obtained $(\times 100)$. c Single cell-derived colonies were obtained after culture for 14 days $(\times 40)$. Alizarin Red staining was performed to detect mineral nodes in the control group $(\mathbf{d})$ and experimental group (e) (× 100). f-k Flow cytometric analysis of the surface markers of hDPSCs. Cells were incubated with fluorescently conjugated antibodies against CD29, CD90, CD44, CD105, CD34, and CD45. Isotype-identical antibodies served as controls. Analysis of molecular surface antigen markers in hDPSCs by flow cytometry indicated that the cells were positive for CD29, CD44, CD90, and CD105 and negative for CD34 and CD45

\section{Dual-luciferase reporter assay}

TargetScan online bioinformatics software (http://www. targetscan.org) was used to identify the underlying binding sites of miR-588, G043225, and FBN1. The miR-588 target binding sequences estimated in wild-type and mutant G043225 and FBN1 were synthesized and cloned downstream of luciferase gene in pmirGLO luciferase vector (GeneChem, Shanghai, China). Plasmids were used as standard controls, and luciferase plasmids (GeneChem, Shanghai, China) were transfected into 293T cells using Lipofectamine 2000 (Thermo Fisher Scientific, Waltham, MA, USA). Firefly and renal luciferase activities were continuously measured by dual-luciferase assay after transfection of $48 \mathrm{~h}$.

\section{qRT-PCR}

Total RNA was isolated from cells using TRIzol (Thermo Fisher Scientific, Waltham, MA, USA), and RNA was reverse-transcribed into cDNA by the PrimeScript RT reagent kit (EZBioscience, Roseville, USA). SYBR Green premix Ex Taq (Takara Bio, Tokyo, Japan) was used for subsequent qRT-PCR amplification on an LC480 system. Glyceraldehyde-3-phosphate dehydrogenase (GAPDH) and U6 were used as internal controls. The sequences of gene-specific primers are listed in Table 1.

\section{Western blotting}

Cells were lysed in RIPA buffer (Beyotime, Nanjing, China) supplement with protease inhibitors. Protein samples were separated by sodium dodecyl sulfate polyacrylamide gel electrophoresis (SDS-PAGE) in 15\% gel and transferred to polyvinylidene difluoride (Amersham, Little Chalfont, UK) at $200 \mathrm{~mA}$ for $2-3 \mathrm{~h}$. The membrane was blocked with $5 \%$ skim milk for $1 \mathrm{~h}$ and incubated with primary antibody overnight at $4{ }^{\circ} \mathrm{C}$. After washed with Trisbuffer saline containing $0.05 \%$ Tween 20 (TBS-T) three times, samples were incubated with the secondary horseradish-peroxidase-conjugated antibody (Proteintech, 

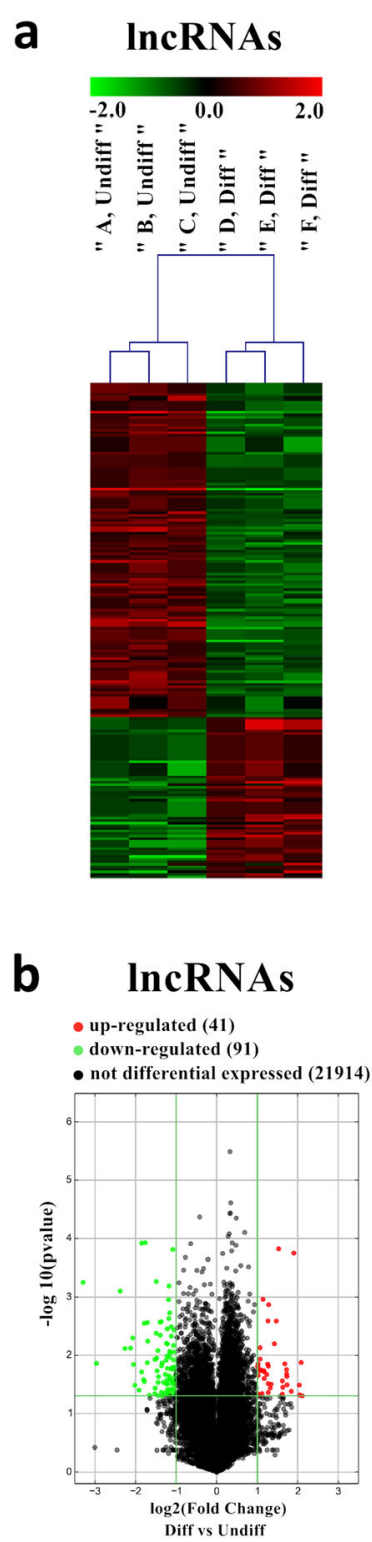
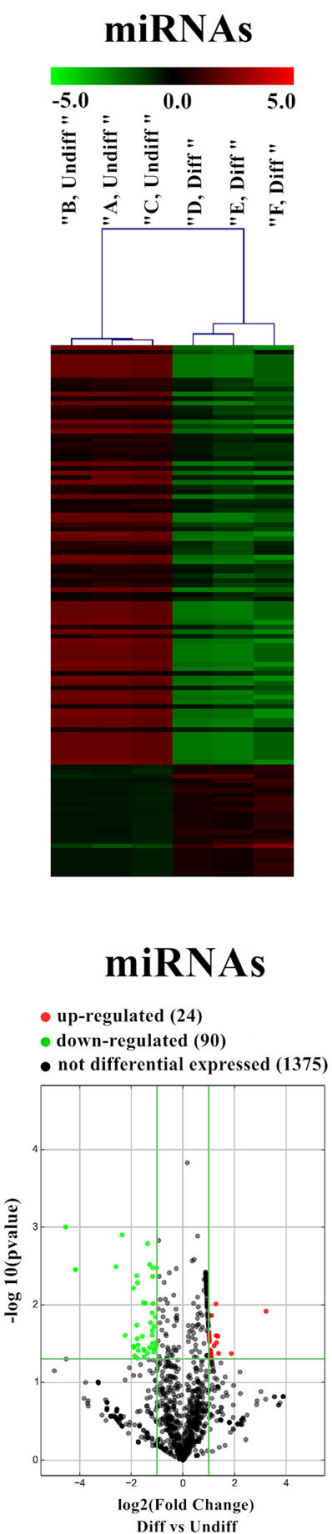

\section{mRNAs}
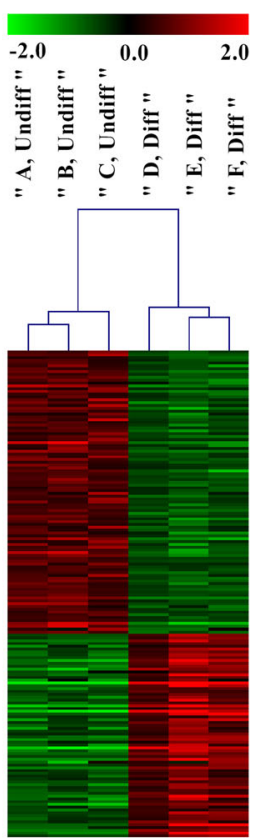

mRNAs

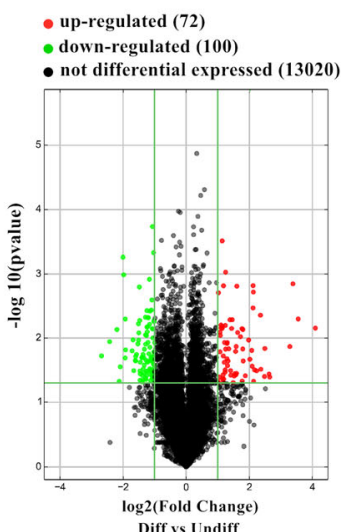

Fig. 3 Microarray profiles of IncRNAs, miRNAs, and mRNAs in three groups of hDPSCs. a Heatmap of differentially expressed RNAs. Screening criteria were as follows: fold change $>2, P<0.05$ for IncRNAs, miRNAs, and mRNAs. The expression value is described by color scale. The intensity increased from green to red. Each column represents one sample, and each row represents one transcript. $\mathbf{b}$ Volcano map of differentially expressed RNAs. Volcano map reflected the number, significance, and reliability of differentially expressed IncRNAs, miRNAs, and mRNAs. The abscissa is $\log 2$ (fold change value), and the ordinate is - $\log 10$ ( $P$ value). Green dots are downregulated genes, red dots are upregulated genes, and gray dots are genes with no significant difference. diff, differentiated; IncRNA, long noncoding RNA; miRNA, microRNA; mRNA, messenger RNA; undiff, undifferentiated

China). Immunoreactive proteins were visualized by using ECL Kit (Beyotime Biotech, Shanghai, China). The gray value of protein bands was calculated by image J software.

\section{Statistical analysis}

Each data point was expressed as the means \pm standard deviation (SD), and the assay was repeated at least three times. Statistical analysis was performed by $t$ test and one-way ANOVA using SPSS 17.0 for Windows (SPSS,
Chicago, IL, USA). Statistical significance was defined as $P<0.05$.

\section{Results}

Characteristics of hDPSCs

After approximately 14 days of culture, the cells emerged from the tissue mass adhering to the culture dish and showed obvious fibroblast-like morphology (Fig. 2a). The hDPSCs used in this study were obtained using limited 

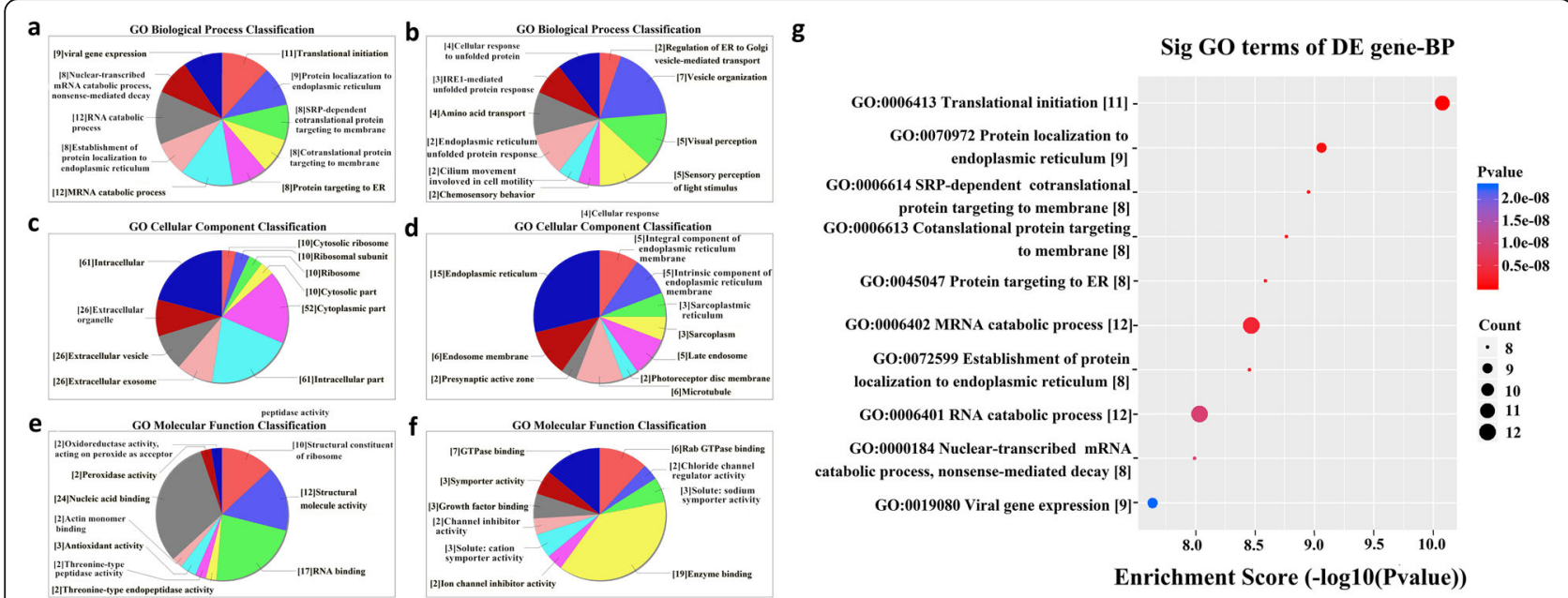

Fig. $4 \mathrm{GO}$ annotation analyses of differentially expressed mRNAs. a GO biological process classification of upregulated mRNAs. b GO biological process classification of downregulated mRNAs. c GO cellular component classification of upregulated mRNAs. d GO cellular component classification of downregulated mRNAs. e GO molecular function classification of upregulated mRNAs. $\mathbf{f} G O$ molecular function classification of downregulated mRNAs. $\mathbf{g}$ The enrichment score values of the top ten significantly enriched terms

dilution technique (Fig. 2b, c). After 14 days of odontogenic induction, mineralized nodules at the differentiated and undifferentiated groups could be observed by Alizarin Red staining (Fig. 2d, e). Flow cytometry was used to analyze cell surface markers. The cells were found to be positive for CD29, CD44, CD90, and CD105 and negative for CD34 and CD45 (Fig. 2f-k).

\section{IncRNA, miRNA, and mRNA profile}

Hierarchical clustering and volcano plot showed that the expression levels of lncRNAs, miRNAs, and mRNAs in the differentiated group differed significantly from those in the undifferentiated group according to fold change (greater than 2) and $P$ value (less than 0.05). Among these, 41 lncRNAs were upregulated and 91 were downregulated, 24 miRNAs were upregulated and 90 were downregulated, and 72 mRNAs were upregulated and 100 were downregulated (Fig. 3). The details of dysregulated lncRNAs, miRNAs, and mRNAs are shown in Supplementary Tables 1, 2, 3, 4, 5, and 6 .

\section{Molecular function and pathway prediction}

The most enriched BP terms related to odontogenic differentiation were regulation of cell differentiation, regulation of Notch signaling pathway, regulation of canonical Wnt signaling pathway, regulation of epidermal growth factor receptor (ERBB) signaling pathway, and activation of mitogen-activated protein kinase (MAPK) activity. The most enriched MF terms were nucleic acid binding, RNA binding, protein binding, etc. The most enriched $\mathrm{CC}$ terms were organelle part, intracellular organelle part, endomembrane system, etc. The enrichment score values of the top ten significantly enriched terms are shown in Fig. 4. The most significant pathway was forkhead box $\mathrm{O}$ (FoxO) signaling pathway, which is related to odontogenic differentiation (Fig. 5).

\section{Regulatory network of miRNAs/odontogenesis-related genes}

According to previous reports [31-34], 4 targets related to odontogenesis were identified from the differentially expressed mRNAs. Among the 4 mRNAs, DNA damage inducible transcript 3 (DDIT3) and FBN1 were upregulated, while rhodopsin (RHO) and NKD inhibitor of WNT signaling pathway 2 (NKD2) were downregulated. Twenty miRNAs regulating these 4 targets were predicted using the TargetScan and miRanda algorithm (Fig. 6a).

\section{IncRNA-miRNA-mRNA network construction and visualization}

Among these 4 odontogenesis-related genes, the upregulated gene FBN1 and the downregulated gene RHO were centered and lncRNA-associated ceRNA networks were successfully constructed (Fig. 6b, c). As shown in Fig. 6c, 2 lncRNAs (G043225 and G055009), 3 miRNAs (miR4717-3p, miR-32-5p, and miR-588), and FBN1 were included. The binding sites of miR-4717-3p with FBN1 are TCATGTG, while the binding sites of miR-4717-3p with G055009 are CCATGTG. The binding sites of miR-325p with FBN1 and miR-32-5p with G055009 share the same sequences GTGCAAT. The binding site sequence of miR-588 with FBN1 and miR-588 with G043225 is GTGGCCA (Fig. 7). 


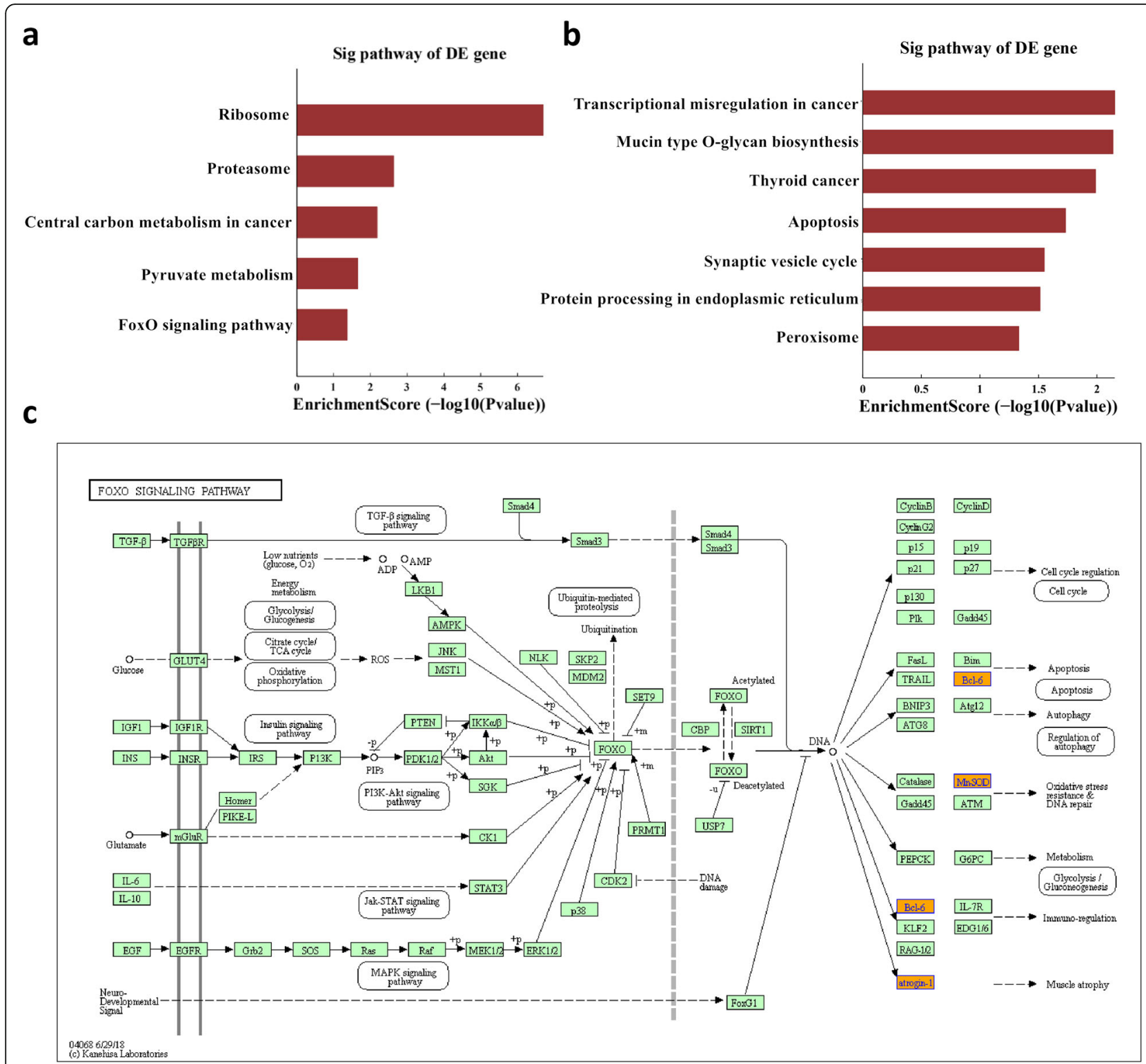

Fig. 5 KEGG pathway analyses of differentially expressed mRNAs. a KEGG pathway analysis of upregulated mRNAs. $\mathbf{b}$ KEGG analysis of downregulated mRNAs. c FoxO signaling pathway map. Upregulated genes in the microarray results are marked in red. Sig, signal; DE, differentially expressed

\section{qRT-PCR validation}

Ten differentially expressed lncRNAs, 3 miRNAs, and 4 odontogenesis-related genes were selected and validated using qRT-PCR. The validation results were consistent with the microarray analysis data (Fig. 8).

\section{The location and function of G043225}

According to the results of $\mathrm{qRT}-\mathrm{PCR}$ validation and ceRNA network, G043225 was selected for further researches. FISH array revealed that G043225 was mainly distributed in the cytoplasm of hDPSCs (Fig. 9a-c).
ARS staining revealed that knocking down G043225 inhibited the mineralization after 14 days of odontogenic induction (Fig. 9d-g), whereas ALP staining in the shRNA-G043225 group at 7 days was less than the shRNA-ctrl group (Fig. 9h-k). At 14 days of the odontogenic induction, the mRNA expression levels of dentin sialophosphoprotein (DSPP) and RUNX family transcription factor 2 (RUNX2) in the shRNA-G043225 group were significantly lower than the shRNA-ctrl group (Fig. 9l, m). Western blot analyses also confirmed that after 14 days of odontogenic induction, the protein 


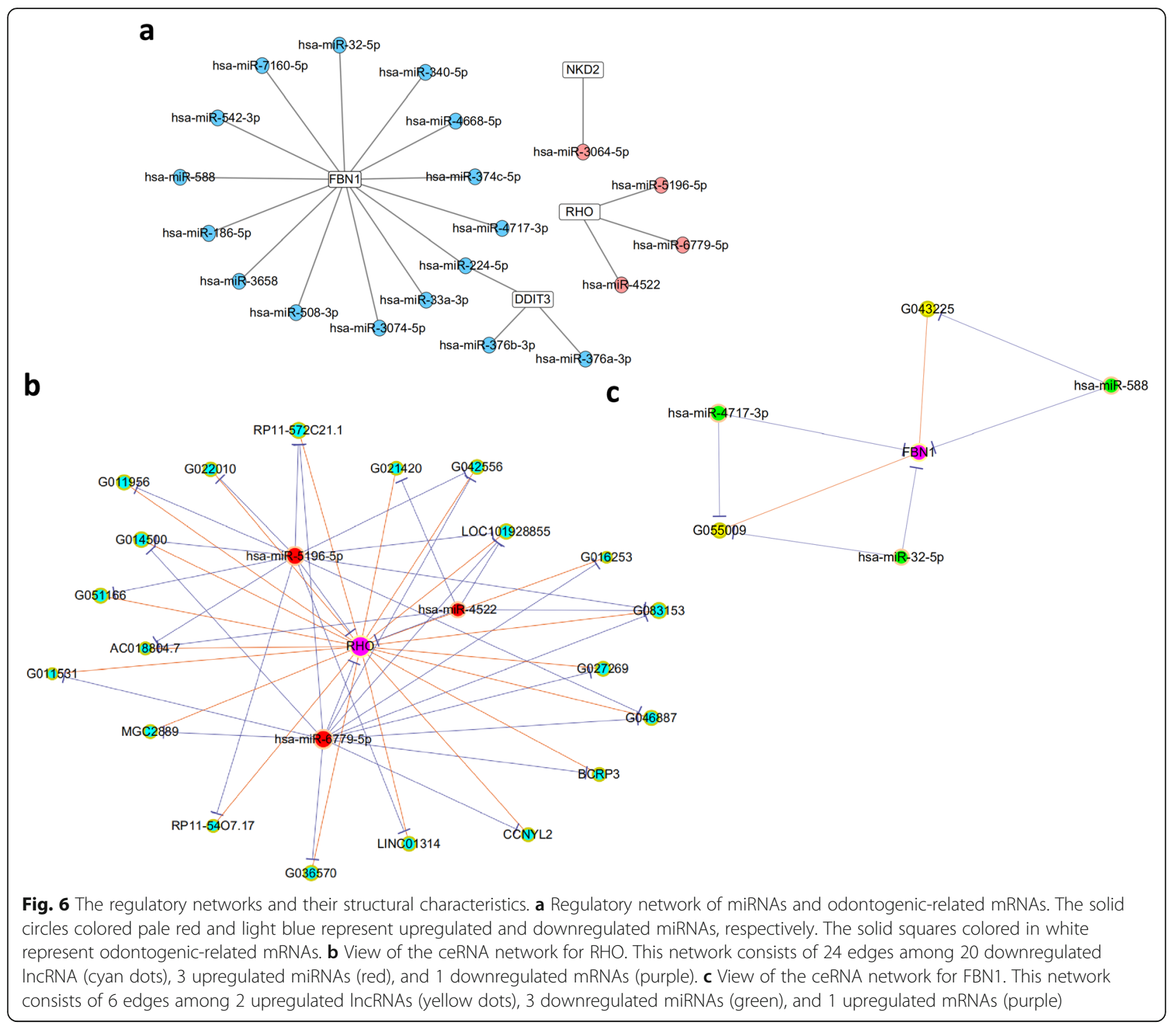

levels of DSPP and RUNX2 were also decreased in the G043225 knockdown group (Fig. 9n-p).

Furthermore, the results of the dual-luciferase reporter showed that miR-588 overexpression significantly decreased the luciferase activity of G043225-WT and FBN1-WT (Fig. 10a, b), indicating that miR-588 could directly bind with both G043225 and FBN1. In addition, the results of qRT-PCR and western blot analysis revealed that the G043225 silencing upregulated miR-588 and downregulated FBN1 at mRNA and protein levels (Fig. 10c-e).

\section{Discussion}

lncRNA-associated ceRNA plays an important role in cell differentiation. Feng et al. [35] reported that linc-ROR promotes osteogenic differentiation of mesenchymal stem cells (MSCs) by functioning as a ceRNA for miR-138 and miR-145. Jia et al. [30] reported LINC00707 sponges miR370-3p to promote osteogenesis of human bone marrowderived MSCs through upregulating WNT2B, indicating that ceRNA may play a significant role in the process of cell differentiation, but its role in the process of odontogenic differentiation needs further exploration. To our knowledge, this is the first study to report on lncRNAassociated ceRNA regulation in the odontogenic differentiation of hDPSCs using microarray. IncRNAs often express and function at low abundance, buried in other classes of abundant RNAs. There are serious limitations and many errors in the process of RNA-Seq data analysis, exon detection, and RNA quantification [36, 37]. The microarray annotation and analyses are rich, detailed, and comprehensive, unrivaled by any other profiling platforms, 


\section{a}

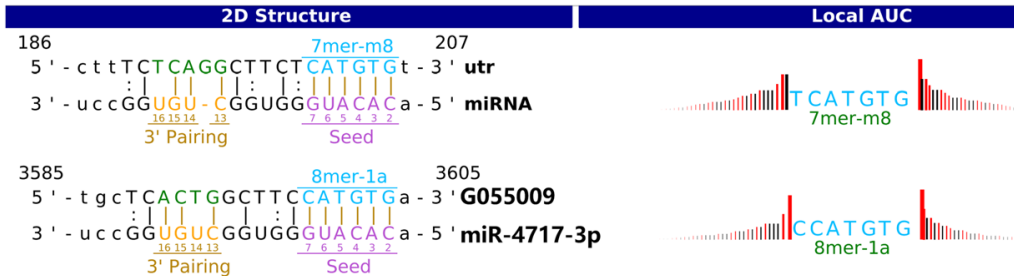

b

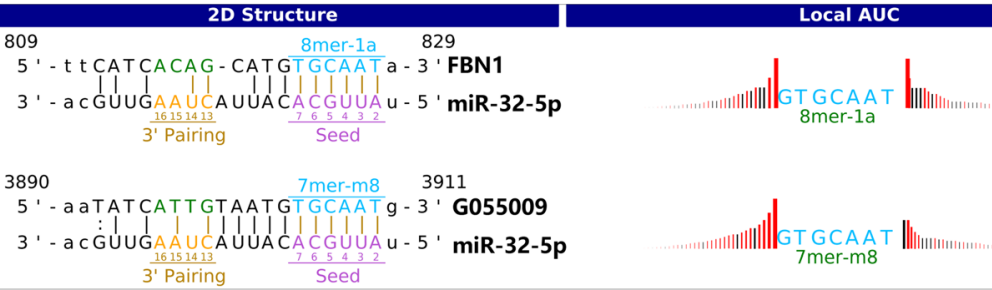

C

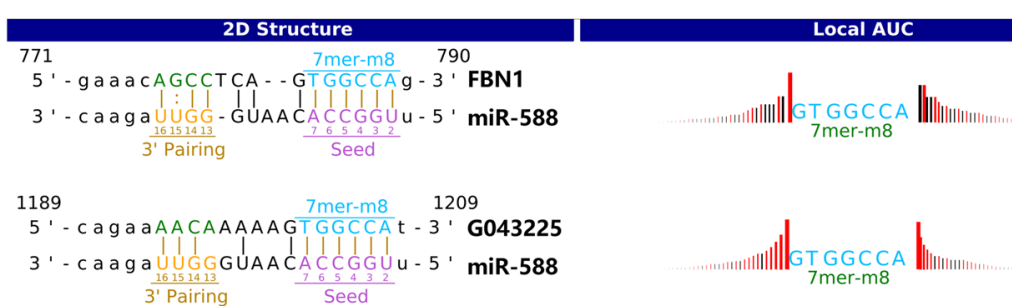

Fig. 7 Schematic representation of the putative binding sites of miRNA sequences with mRNA and IncRNA. a FBN1 and IncRNA-G055009 binding sequence in the $5^{\prime}$ region of miR-4717-3p. b FBN1 and IncRNA-G055009 binding sequence in the $5^{\prime}$ region of miR-32-5p. c FBN1 and IncRNAG043225 binding sequence in the $5^{\prime}$ region of miR-588

so it is still the preferred platform for lncRNA expression profile detection $[38,39]$. Therefore, in this study, we used the microarray to detect lncRNA, miRNA, and mRNA expression. Our findings provide an explanation for the mechanism role of lncRNA in odontogenesis. Further indepth functional investigations would extend our knowledge of the roles of lncRNA-miRNA-mRNA networks in the odontogenic differentiation of hDPSCs.

When dental pulp is stimulated by infection or trauma, hDPSCs can form new odontoblasts and reparative dentine, which can protect dental pulp from further damage [40]. In the research on ncRNAs and their roles in the odontogenic differentiation of hDPSCs, the most studied are miRNAs. miR-223-3p and miR-21 have been shown to promote odontogenic differentiation, while miR-143-5p, miR-140-5p, and miR-488 inhibit this process [41-46]. In 2016, Chen et al. found that IncRNA differentiation antagonizing non-protein coding RNA (DANCR) inhibited the odontogenic differentiation of human dental pulp cells by inactivating the Wnt/ $\beta$-catenin signaling pathway [16]. One recent study revealed that lncRNA H19 promoted the odontogenic differentiation of hDPSCs.
The author further found that the H19/SAHH axis could epigenetically regulate odontogenic process [15]. To date, few studies have investigated the lncRNAassociated ceRNA networks during odontogenic differentiation of hDPSCs.

The IncRNA-associated ceRNA mechanism has been demonstrated in the multilineage differentiation of MSCs. In this study, we used a genome-wide microarray to detect the differentially expressed lncRNAs, miRNAs, and mRNAs between differentiated and undifferentiated hDPSCs, and focused on the crosstalk between lncRNAs and miRNAs to provide insights into ncRNA coordination for odontogenesis regulation. According to previous reports, four odontogenesis-related genes were identified. Among the four target genes, FBN1 and RHO were used to successfully construct specific ceRNA networks with the corresponding miRNAs and lncRNAs. However, exploration of the ceRNA mechanism of lncRNAs in previous literature indicated that the subcellular localization of lncRNAs is rarely mentioned, even though this localization is the basis of the ceRNA mechanism. For example, if a lncRNA is mainly located in the nucleus, it will not play a major 


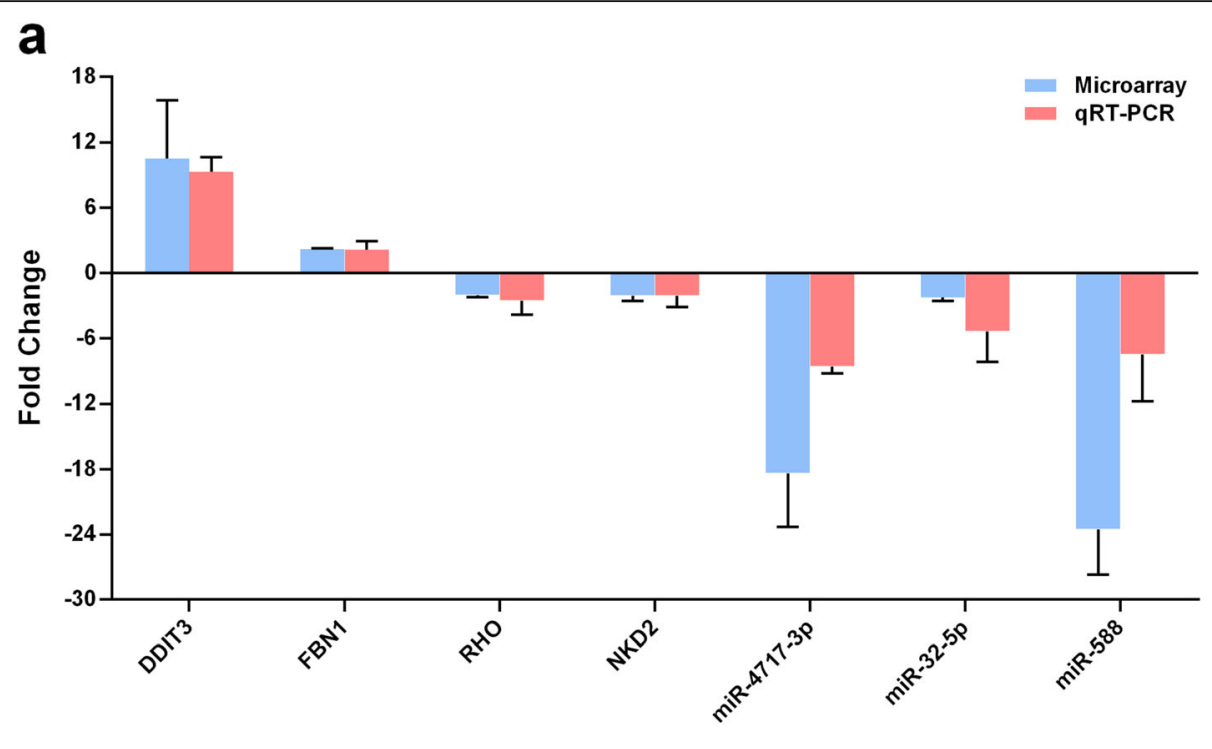

b

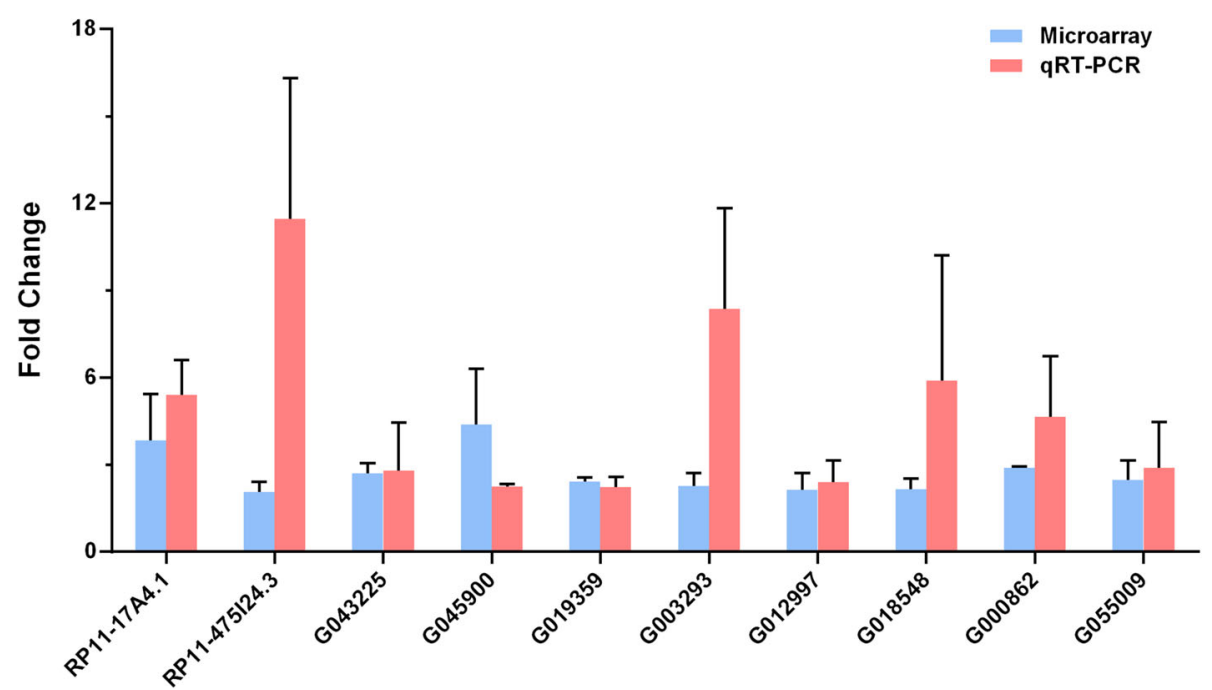

Fig. 8 Comparison of microarray and qRT-PCR data for candidate RNAs. a Odontogenesis-related mRNAs and miRNAs. b Candidate IncRNAs. Heights of the columns in the chart represented mean fold changes in expression for each of the mRNA, miRNAs, and IncRNAs. Four odontogenesis-related mRNAs, three downregulated miRNAs, and ten upregulated IncRNAs were validated by qRT-PCR. Validation results were consistent with the microarray data

regulatory role through a ceRNA mechanism $[47,48]$. In further research concerning the ceRNA mechanism, the subcellular localization of IncRNAs in hDPSCs must be demonstrated.

In addition, miRNA targets and lncRNA-associated ceRNA networks were constructed, and this could provide clues to explore the mechanism of action at the RNA-RNA level. The verification of differentially expressed IncRNAs, miRNAs, and mRNAs by qRTPCR further improved the credibility of our network. However, we should also take into account that in addition to these four target genes, other significantly differentially expressed target genes might also play an important regulatory role. For example, B cell lymphoma 6 (BCL6) and superoxide dismutase 2 (SOD2) are related to the FoxO signaling pathway according to the KEGG analysis. These two genes have been reported to be involved in osteogenic differentiation [49-51]. Therefore, we assume that these two genes might have potential role in the odontogenic differentiation of hDPSCs, but further exploration is needed. 


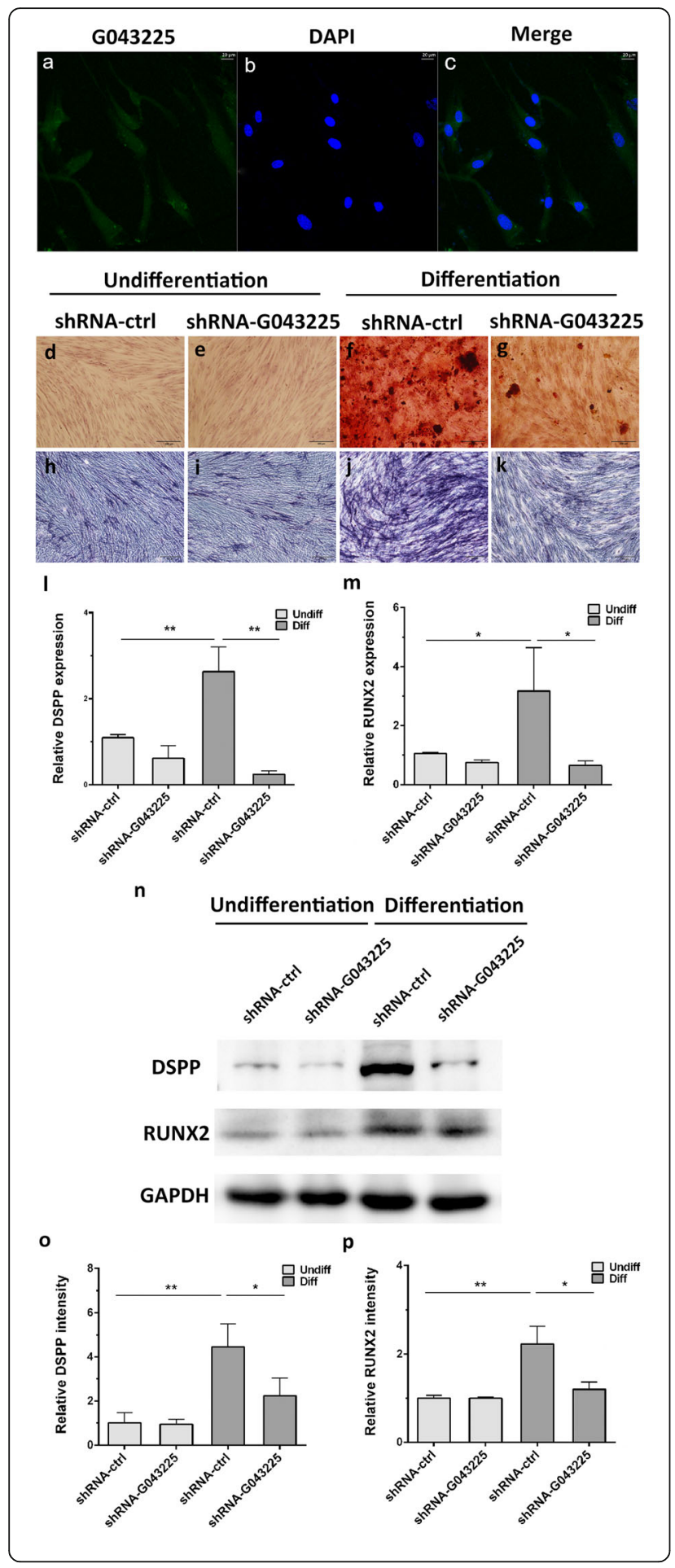

Fig. 9 The location and function of G043225. a-c Expression of G043225 (green) as detected by fluorescence in situ hybridization array. Nuclei (blue) were counterstained with DAPI. d-g G043225 knockdown inhibited mineralization, indicated by Alizarin Red staining at 14 days after odontogenic induction. h-k G043225 knockdown inhibited mineralization, indicated by ALP staining at 7 days after odontogenic induction. I, $\mathbf{m}$ The expression level of DSPP and RUNX2 decreased in the shRNA-G043225 group at 14 days after odontogenic differentiation using qRT-PCR. $\mathbf{n}-\mathbf{p}$ Western blot analysis shows the expression level of DPSS and RUNX2 decreased in the shRNA-G043225 group after odontogenic differentiation for 14 days. GAPDH was used as an internal control. Data represent means $\pm S D$. ${ }^{*} P<0.05,{ }^{*} P<0.01$ compared with differentiated shRNA-ctrl group

GO analysis indicated that several important terms relating to odontogenic differentiation were enriched. They included the regulation of cell differentiation, regulation of Notch signaling pathway, regulation of canonical Wnt signaling pathway, and activation of MAPK activity [5254]. Furthermore, in order to elucidate the potentially relevant signaling pathway, KEGG pathway analysis was used to show the relationships between pathways and genes. This analysis found that FoxO signaling pathway was enriched in odontogenic-differentiated hDPSCs [51]. The results revealed that this pathway might play a crucial role in the odontogenic differentiation of hDPSCs, but the functions need further exploration.

In our research, IncRNA DANCR and H19 expression were not be significantly detected. There are several reasons for this result. First, the differentiated and undifferentiated cells were derived from different people in different studies, which might result in different results. Second, the phenotypic differences can affect the results. Third, different sequencing methods might contribute to the difference. Therefore, large-scale studies are needed to confirm the results.

To further elucidate the ceRNA network, the function and potential mechanism of G043225 were explored. Functional assays showed the promoting role of G043225 in odontogenic differentiation of hDPSCs. The results that G043225 was mainly located in cytoplasm from FISH array further suggested G043225 might play an important role during the odontogenic differentiation of hDPSCs through ceRNA mechanism. Moreover, the target miR-588 was upregulated and its downstream FBN1 was downregulated after interfering G043225. The results of dual-luciferase reporter revealed miR-588 could directly bind with both G043225 and FBN1. The above data demonstrated that G043225-related ceRNA network played an important role in the odontogenic differentiation of hDPSCs. The function of miR-588 and related rescue experiments are warranted for further validation. 

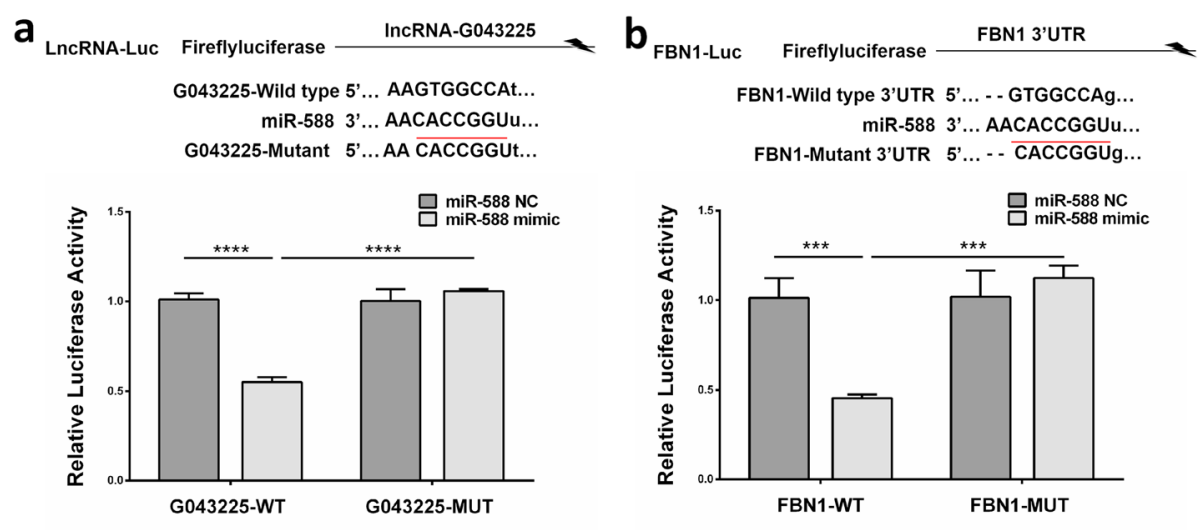

C

d
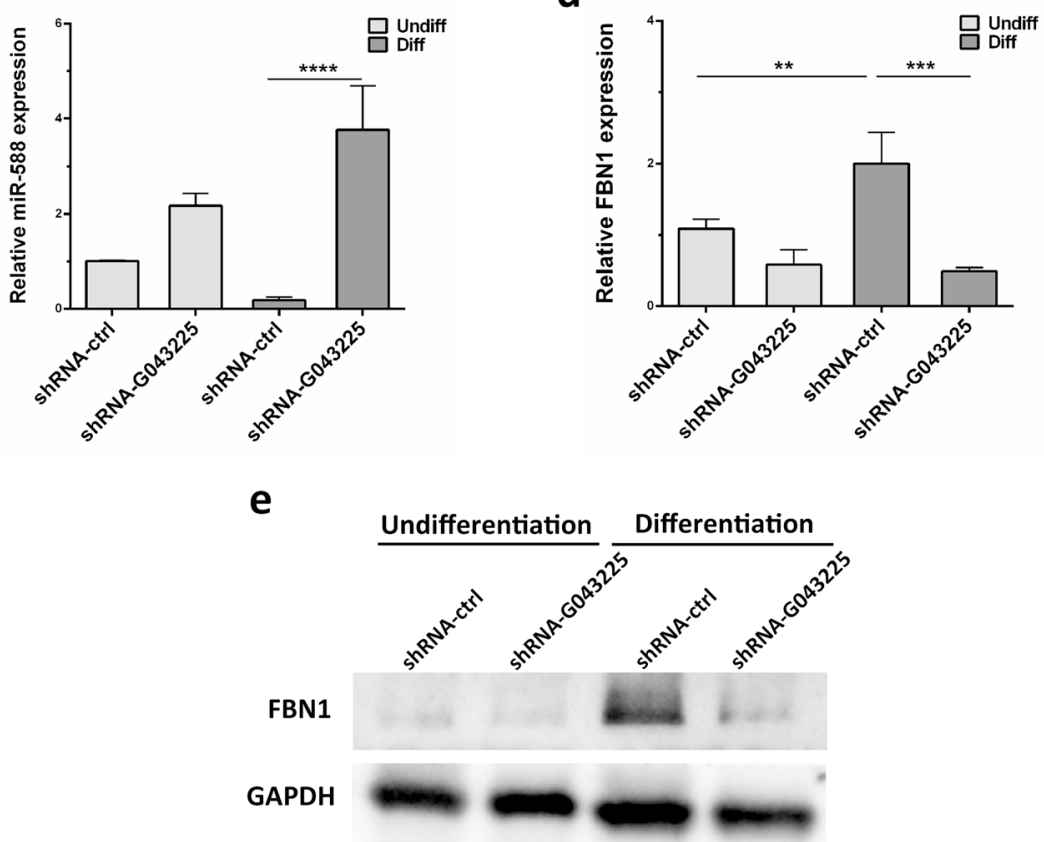

Fig. 10 The potential relationship between G043225, miR-588, and FBN1. a, b Dual-luciferase reporter assay was used to detect the binding sites between G043225 and miR-588, and FBN1 and miR-588. Ectopic expression of miR-588 led to a significant decrease of the reporter luciferase activity with the WT (wild type) but not that of the MUT (mutant) reporter. c The increased expression level of miR-588 was determined following interference of G043225 at 14 days after the odontogenic induction by qRT-PCR. $\mathbf{d}$, e The decreased mRNA and protein expression level of FBN1 was determined in hDPSCs following interference of G043225 at 14 days after the odontogenic induction by qRT-PCR and western blot. GAPDH was used as an internal control. Data represent the mean \pm S.D. ${ }^{*} P<0.05$, ${ }^{* *} P<0.01,{ }^{* *} P<0.001$, ${ }^{* * *} P<0.0001$ compared with differentiated shRNA-ctrl group

\section{Conclusion}

In summary, to the best of our knowledge, this is the first study revealing the lncRNA-associated ceRNA network during odontogenic differentiation of hDPSCs using microarray. Although the specific role and mechanism of the candidate lncRNAs in the odontogenic differentiation of hDPSCs require further investigation, our findings extended the current knowledge on the odontogenic process of hDPSCs and suggested directions for further investigations on the regulation of odontogenic differentiation of hDPSCs as well as treatments for dentin regeneration based on stem cells.

\section{Supplementary information}

Supplementary information accompanies this paper at https://doi.org/10. 1186/s13287-020-01622-w.

Additional file 1: Table S1. The expression profiles of upregulated IncRNAs in differentiated and undifferentiated hDPSCs. (XLS $72 \mathrm{~kb}$ ) 
Additional file 2: Table S2. The expression profiles of downregulated IncRNAs in differentiated and undifferentiated hDPSCs. (XLS $119 \mathrm{~kb}$ )

Additional file 3: Table S3. The expression profiles of upregulated miRNAs in differentiated and undifferentiated hDPSCs. (XLS 33 kb)

Additional file 4: Table S4. The expression profiles of downregulated miRNAs in differentiated and undifferentiated hDPSCs. (XLS $63 \mathrm{~kb}$ )

Additional file 5: Table S5. The expression profiles of upregulated mRNAs in differentiated and undifferentiated hDPSCs. (XLS $88 \mathrm{~kb}$ )

Additional file 6: Table S6. The expression profiles of downregulated mRNAs in differentiated and undifferentiated hDPSCs. (XLS $108 \mathrm{~kb}$ )

\section{Abbreviations}

BCL6: B cell lymphoma 6; BP: Biological processes; CC: Cellular components; ceRNA: Competitive endogenous RNA; DANCR: Differentiation antagonizing non-protein coding RNA; DDIT3: DNA damage inducible transcript 3; DE: Differentially expressed; DERNAs: Differentially expressed RNAs; DMEM: Dulbecco's modified Eagle's medium; DSPP: Dentin sialophosphoprotein; ERBB: Epidermal growth factor receptor; FBN1: Fibrillin 1; FBS: Fetal bovine serum; FISH: Fluorescence in situ hybridization; FoxO: Forkhead box O; GAPDH: Glyceraldehyde-3-phosphate dehydrogenase; GO: Gene Ontology; hDPCs: Human dental pulp cells; hDPSCs: Human dental pulp stem cells; KEGG: Kyoto Encyclopedia of Genes and Genomes; IncRNAs: Long noncoding RNAs; MAPK: Mitogen-activated protein kinase; MF: Molecular functions; miRNAs: MicroRNAs; mRNA: Messenger RNA; MSCs: Mesenchymal stem cells; ncRNAs: Noncoding RNAs; NKD2: NKD inhibitor of WNT signaling pathway 2; Notch: Neurogenic locus notch homolog: PBS: Phosphate buffer solution; qRT-PCR: Quantitative reversetranscription polymerase chain reaction; RHO: Rhodopsin; RUNX2: RUNX family transcription factor 2; SD: Standard deviation; Sig: Signal; SOD2: Superoxide dismutase 2

\section{Acknowledgements}

Not applicable.

\section{Authors' contributions}

FFC and WBL contributed to the conception and logic of the article. FFC, CZ, and LYF contributed to the writing and drafting of the manuscript. CZ, LYF, and ZKY performed the experiments, collection of data, data analysis, and interpretation. PYH, LJ, and YYQ contributed to the data analysis and interpretation. FFC, WBL, and OW contributed to the critical revision of the manuscript for important intellectual content; all the authors have given final approval of the version to be published and agree to be accountable for all aspects of the work

\section{Funding}

This study was supported by the National Natural Science Foundation of China $(81600882,81870755)$

\section{Availability of data and materials}

The data supporting the research results obtained from the corresponding authors according to reasonable requirements.

\section{Ethics approval and consent to participate}

This study was approved by the Ethics Committee of Nanfang Hospital, Southern Medical University. Written informed consent was obtained from all adult patients. For minor population, statement on informed consent was obtained from their parents.

\section{Consent for publication}

Not applicable.

\section{Competing interests}

The authors declare that they have no competing interests.
Received: 3 October 2019 Revised: 3 February 2020

Accepted: 26 February 2020 Published online: 13 March 2020

\section{References}

1. Gronthos S, Mankani M, Brahim J, Robey PG, Shi S. Postnatal human dental pulp stem cells (DPSCs) in vitro and in vivo. Proc Natl Acad Sci U S A. 2000; 97:13625-30.

2. Sloan AJ, Smith AJ. Stem cells and the dental pulp: potential roles in dentine regeneration and repair. Oral Dis. 2007;13:151-7.

3. Peng $L$, Ye $L$, Zhou XD. Mesenchymal stem cells and tooth engineering. Int J Oral Sci. 2009;1:6-12.

4. Ferro F, Spelat R, Baheney CS. Dental pulp stem cell (DPSC) isolation, characterization, and differentiation. Methods Mol Biol. 2014;1210:91-115.

5. Mead B, Logan A, Berry M, Leadbeater W, Scheven BA. Concise review: dental pulp stem cells: a novel cell therapy for retinal and central nervous system repair. Stem Cells. 2017;35:61-7.

6. Gay I, Cavender A, Peto D, Sun Z, Speer A, Cao H, Amendt BA. Differentiation of human dental stem cells reveals a role for microRNA-218. J Periodontal Res. 2014;49:110-20.

7. Victor AK, Reiter LT. Dental pulp stem cells for the study of neurogenetic disorders. Hum Mol Genet. 2017;26:R166-71.

8. Nuti N, Corallo C, Chan BM, Ferrari M, Gerami-Naini B. Multipotent differentiation of human dental pulp stem cells: a literature review. Stem Cell Rev Rep. 2016:12:511-23.

9. Li D, Zou XY, El-Ayachi I, Romero LO, Yu Z, Iglesias-Linares A, CorderoMorales JF, Huang GT. Human dental pulp stem cells and gingival mesenchymal stem cells display action potential capacity in vitro after neuronogenic differentiation. Stem Cell Rev Rep. 2019;15:67-81.

10. Cooper PR, Takahashi Y, Graham LW, Simon S, Imazato S, Smith AJ. Inflammation-regeneration interplay in the dentine-pulp complex. J Dent. 2010:38:687-97.

11. Akhade VS, Pal D, Kanduri C. Long noncoding RNA: genome organization and mechanism of action. Adv Exp Med Biol. 2017;1008:47-74.

12. Kanduri C. Long noncoding RNAs: lessons from genomic imprinting. Biochim Biophys Acta. 1859;2016:102-11.

13. Taylor DH, Chu ET, Spektor R, Soloway PD. Long non-coding RNA regulation of reproduction and development. Mol Reprod Dev. 2015:82:932-56.

14. Chen LL. Linking long noncoding RNA localization and function. Trends Biochem Sci. 2016:41:761-72

15. Zeng L, Sun S, Han D, Liu Y, Liu H, Feng H, Wang Y. Long non-coding RNA H19/SAHH axis epigenetically regulates odontogenic differentiation of human dental pulp stem cells. Cell Signal. 2018;52:65-73.

16. Chen L, Song Z, Huang S, Wang R, Qin W, Guo J, Lin Z. IncRNA DANCR suppresses odontoblast-like differentiation of human dental pulp cells by inhibiting wnt/beta-catenin pathway. Cell Tissue Res. 2016;364:309-18.

17. Xiao H, Zhang F, Zou Y, Li J, Liu Y, Huang W. The function and mechanism of long non-coding RNA-ATB in cancers. Front Physiol. 2018;9:321.

18. Qu Q, Fang F, Wu B, Hu Y, Chen M, Deng Z, Ma D, Chen T, Hao Y, Ge Y. Potential role of long noncoding RNA in the osteogenic differentiation of human periodontal ligament stem cells. J Periodontol. 2016;87:e127-37.

19. Zhang J, Hao X, Yin M, Xu T, Guo F. Long non-coding RNA in osteogenesis: a new world to be explored. Bone Joint Res. 2019:8:73-80.

20. Kopp F, Mendell JT. Functional classification and experimental dissection of long noncoding RNAs. Cell. 2018;172:393-407.

21. Wu H, Yang L, Chen LL. The diversity of long noncoding RNAs and their generation. Trends Genet. 2017:33:540-52.

22. Tay Y, Rinn J, Pandolfi PP. The multilayered complexity of ceRNA crosstalk and competition. Nature. 2014;505:344-52.

23. Cui L, Xu S, Ma D, Gao J, Liu Y, Yue J, Wu B. The role of integrin-alpha5 in the proliferation and odontogenic differentiation of human dental pulp stem cells. J Endod. 2014;40:235-40.

24. Ge Y, Li J, Hao Y, Hu Y, Chen D, Wu B, Fang F. MicroRNA-543 functions as an osteogenesis promoter in human periodontal ligament-derived stem cells by inhibiting transducer of ERBB2, 2. J Periodontal Res. 2018;53:832-41.

25. Grimson A, Farh KK, Johnston WK, Garrett-Engele P, Lim LP, Bartel DP. MicroRNA targeting specificity in mammals: determinants beyond seed pairing. Mol Cell. 2007;27:91-105

26. Bai $Y$, Long J, Liu Z, Lin J, Huang $H$, Wang $D$, Yang $X$, Miao F, Mao $Y$, Sang $X$ Zhao $\mathrm{H}$. Comprehensive analysis of a ceRNA network reveals potential prognostic cytoplasmic IncRNAs involved in HCC progression. J Cell Physiol. 2019;234:18837-48. 
27. Hao Y, Ge Y, Li J, Hu Y, Wu B, Fang F. Identification of microRNAs by microarray analysis and prediction of target genes involved in osteogenic differentiation of human periodontal ligament stem cells. J Periodontol. 2017:88:1105-13.

28. Denzler R, McGeary SE, Title AC, Agarwal V, Bartel DP, Stoffel M. Impact of microRNA levels, target-site complementarity, and cooperativity on competing endogenous RNA-regulated gene expression. Mol Cell. 2016;64: 565-79.

29. Wang C, Wang L, Ding Y, Lu X, Zhang G, Yang J, Zheng H, Wang H, Jiang Y, $\mathrm{Xu} \mathrm{L}$. LncRNA structural characteristics in epigenetic regulation. Int J Mol Sci. 2017;18:E2659.

30. Jia B, Wang Z, Sun X, Chen J, Zhao J, Qiu X. Long noncoding RNA LINC00707 sponges miR-370-3p to promote osteogenesis of human bone marrow-derived mesenchymal stem cells through upregulating WNT2B. Stem Cell Res Ther. 2019;10:67.

31. Wu Y, Sun H, Song F, Fu D, Wang J. DDIT3 overexpression increases odontoblastic potential of human dental pulp cells. Cell Prolif. 2014;47:24957.

32. Yoshiba N, Yoshiba K, Ohkura N, Hosoya A, Shigetani Y, Yamanaka Y, Izumi $\mathrm{N}$, Nakamura H, Okiji T. Expressional alterations of fibrillin-1 during wound healing of human dental pulp. J Endod. 2012;38:177-84.

33. Huang X, Chen X, Chen H, Xu D, Lin C, Peng B. Rho/Rho-associated protein kinase signaling pathway-mediated downregulation of runt-related transcription factor 2 expression promotes the differentiation of dental pulp stem cells into odontoblasts. Exp Ther Med. 2018;15:4457-64.

34. Sagomonyants K, Mina M. Biphasic effects of FGF2 on odontoblast differentiation involve changes in the BMP and Wnt signaling pathways. Connect Tissue Res. 2014;55(Suppl 1):53-6.

35. Feng L, Shi L, Lu YF, Wang B, Tang T, Fu WM, He W, Li G, Zhang JF. Linc ROR promotes osteogenic differentiation of mesenchymal stem cells by functioning as a competing endogenous RNA for miR-138 and miR-145. Mol Ther Nucleic Acids. 2018;11:345-53.

36. Jiang L, Schlesinger F, Davis CA, Zhang Y, Li R, Salit M, Gingeras TR, Oliver B. Synthetic spike-in standards for RNA-seq experiments. Genome Res. 2011;21: 1543-51.

37. Toung JM, Morley M, Li M, Cheung VG. RNA-sequence analysis of human Bcells. Genome Res. 2011;21:991-8.

38. Kretz M, Webster DE, Flockhart RJ, Lee CS, Zehnder A, Lopez-Pajares V, Qu K, Zheng GX, Chow J, Kim GE, Rinn JL, Chang HY, Siprashvili Z, Khavari PA. Suppression of progenitor differentiation requires the long noncoding RNA ANCR. Genes Dev. 2012;26:338-43.

39. Xu W, Seok J, Mindrinos MN, Schweitzer AC, Jiang H, Wilhelmy J, Clark TA, Kapur K, Xing Y, Faham M, Storey JD, Moldawer LL, Maier RV, Tompkins RG, Wong WH, Davis RW, Xiao W. Inflammation and host response to injury large-scale collaborative research program. Human transcriptome array for high-throughput clinical studies. Proc Natl Acad Sci U S A. 2011;108:370712.

40. Farges JC, Alliot-Licht B, Renard E, Ducret M, Gaudin A, Smith AJ, Cooper PR. Dental pulp defence and repair mechanisms in dental caries. Mediat Inflamm. 2015;2015:230251.

41. Huang X, Liu F, Hou J, Chen K. Inflammation-induced overexpression of microRNA-223-3p regulates odontoblastic differentiation of human dental pulp stem cells by targeting SMAD3. Int Endod J. 2019;52:491-503.

42. Xu K, Xiao J, Zheng K, Feng X, Zhang J, Song D, Wang C, Shen X, Zhao X, Wei $C$, Huang D, Feng G. MiR-21/STAT3 signal is involved in odontoblast differentiation of human dental pulp stem cells mediated by TNF-a. Cell Reprogram. 2018;20:107-16.

43. Zhan FL, Liu XY, Wang XB. The role of microRNA-143-5p in the differentiation of dental pulp stem cells into odontoblasts by targeting Runx2 via the OPG/RANKL signaling pathway. J Cell Biochem. 2018;119:53646.

44. Wang BL, Wang Z, Nan X, Zhang QC, Liu W. Downregulation of microRNA$143-5 p$ is required for the promotion of odontoblasts differentiation of human dental pulp stem cells through the activation of the mitogenactivated protein kinases 14-dependent p38 mitogen-activated protein kinases signaling pathway. J Cell Physiol. 2019;234:4840-50.

45. Sun DG, Xin BC, Wu D, Zhou L, Wu HB, Gong W, Lv J. miR-140-5p-mediated regulation of the proliferation and differentiation of human dental pulp stem cells occurs through the lipopolysaccharide/toll-like receptor 4 signaling pathway. Eur J Oral Sci. 2017;125:419-25.
46. Yu D, Zhao X, Cheng JZ, Wang D, Zhang HH, Han GH. Downregulated microRNA-488 enhances odontoblast differentiation of human dental pulp stem cells via activation of the p38 MAPK signaling pathway. J Cell Physiol. 2019:234:1442-51.

47. Fang F, Zhang K, Chen Z, Wu B. Noncoding RNAs: new insights into the odontogenic differentiation of dental tissue-derived mesenchymal stem cells. Stem Cell Res Ther. 2019;10:297.

48. Ju C, Liu R, Zhang YW, Zhang Y, Zhou R, Sun J, Lv XB, Zhang Z. Mesenchymal stem cell-associated IncRNA in osteogenic differentiation. Biomed Pharmacother. 2019;115:108912.

49. Yu G, Wang J, Lin X, Diao S, Cao Y, Dong R, Wang L, Wang S, Fan Z. Demethylation of SFRP2 by histone demethylase KDM2A regulated osteo-/ dentinogenic differentiation of stem cells of the apical papilla. Cell Prolif. 2016:49:330-40.

50. Ding $Y$, Yang $H$, Wang $Y$, Chen J, Ji Z, Sun $H$. Sirtuin 3 is required for osteogenic differentiation through maintenance of PGC-1a-SOD2-mediated regulation of mitochondrial function. Int J Biol Sci. 2017;13:254-64.

51. Liao L, Su X, Yang X, Hu C, Li B, Lv Y, Shuai Y, Jing H, Deng Z, Jin Y. TNFalpha inhibits FoxO1 by upregulating miR-705 to aggravate oxidative damage in bone marrow-derived mesenchymal stem cells during osteoporosis. Stem Cells. 2016;34:1054-67.

52. Liu N, Zhou M, Zhang Q, Zhang T, Tian T, Ma Q, Xue C, Lin S, Cai X. Stiffness regulates the proliferation and osteogenic/odontogenic differentiation of human dental pulp stem cells via the WNT signalling pathway. Cell Prolif. 2018;51:e12435

53. Zhou M, Liu NX, Shi SR, Li Y, Zhang Q, Ma QQ, Tian TR, Ma WJ, Cai XX, Lin YF. Effect of tetrahedral DNA nanostructures on proliferation and osteo/ odontogenic differentiation of dental pulp stem cells via activation of the notch signaling pathway. Nanomedicine. 2018;14:1227-36.

54. Ngo VA, Jung JY, Koh JT, Oh WM, Hwang YC, Lee BN. Leptin induces odontogenic differentiation and angiogenesis in human dental pulp cells via activation of the mitogen-activated protein kinase signaling pathway. $J$ Endod. 2018:44:585-91.

\section{Publisher's Note}

Springer Nature remains neutral with regard to jurisdictional claims in published maps and institutional affiliations.
Ready to submit your research? Choose BMC and benefit from:

- fast, convenient online submission

- thorough peer review by experienced researchers in your field

- rapid publication on acceptance

- support for research data, including large and complex data types

- gold Open Access which fosters wider collaboration and increased citations

- maximum visibility for your research: over $100 \mathrm{M}$ website views per year

At BMC, research is always in progress.

Learn more biomedcentral.com/submissions 